\title{
THERMOLUMINESCENCE AS A TECHNIQUE FOR DETERMINING THE NATURE AND HISTORY OF SMALL SOLAR SYSTEM PARTICLES
}

\author{
JONATHAN P. CRAIG ${ }^{1}$ and DEREK W. G. SEARS ${ }^{1,2}$ \\ ${ }^{I}$ Arkansas Center for Space and Planetary Sciences, MUSE 202, University of Arkansas, Fayetteville, AR 72701, USA \\ ${ }^{2}$ Department of Chemistry and Biochemistry, University of Arkansas, Fayetteville, AR 72701, USA
}

Received 13 February 2010

Accepted 21 December 2010

\begin{abstract}
The thermoluminescence phenomenon has been used for pottery dating and radiation dosimetry for sixty years and for forty years has been applied to the study of meteorites, being successful in quantifying metamorphic histories and providing new insights into terrestrial age and orbits. Here we review some of the fundamental properties of thermoluminescence with particular focus on the study of small extraterrestrial particles. We suggest that natural TL data can be used to identify the burial and release history of cometary particles and that induced TL measurements can provide insights into the mineralogy of particles (even when largely amorphous) and the metamorphic history of those particles. We illustrate the use of TL to study small particles by describing recent studies on micrometeorites and 10-100 $\mu \mathrm{m}$ fragments taken from the matrix of a meteorite Semarkona which is type 3.0 ordinary chondrite.
\end{abstract}

Keywords: Thermoluminescence, Stardust mission, Solar System.

\section{INTRODUCTION}

The historic return of dust particles from a comet by the Stardust spacecraft has presented unique opportunities and unique challenges (Fig. 1). The opportunities are self-evident; the samples are important new kind of primitive solar system material (Brownlee et al., 2006; Hörz et al., 2006; Sandford et al., 2006; McKeegan et al., 2006; Keller et al., 2006; Flynn et al., 2006; Zolensky et al., 2006).The challenges are that the samples are tiny, and had to endure capture in the aerogel in which they are now immersed (e.g., Rietmeijer, 2007; Chi et al., 2007). Prior to the return of Stardust samples, Zolensky et al. (2000) summarized some of the opportunities presented by the study of such particles, mentioning particularly (1) mineral paragenesis; (2) regolith processes, (3) bulk composition; (4) conditions of thermal and aqueous alteration (if any); (5) relationships to planets, comets, mete-

Corresponding author: D. W. G. Sears

e-mail: dsears@uark.edu orites (via isotopic analyses, including oxygen); (6) abundance of water and hydrated material; (7) abundance of organics; (8) history of volatile mobility, (9) presence and origin of presolar and/or interstellar material. Zolensky et al. (2000) discuss a wide variety of applicable techniques, but did not include thermoluminescence because at the time it was considered a bulk technique. This is no longer the case, as demonstrated by recent work on micrometeorites and Semarkona matrix fragments (Sedaghatpour and Sears, 2009; Craig and Sears, 2009).

Thermoluminescence is uniquely sensitive and especially suited to detecting trace minerals in an amorphous matrix and providing important characterization. Luminescence studies can provide a new information on the thermal and radiation history and on the solid-state properties (that relate to metamorphic history) of small particles, and on the process of capture in the aerogel. These are very different aspects of the history of these particles. "Thermal history" is the exposure to moderate or high temperatures in a manner that does not change mineralo- 


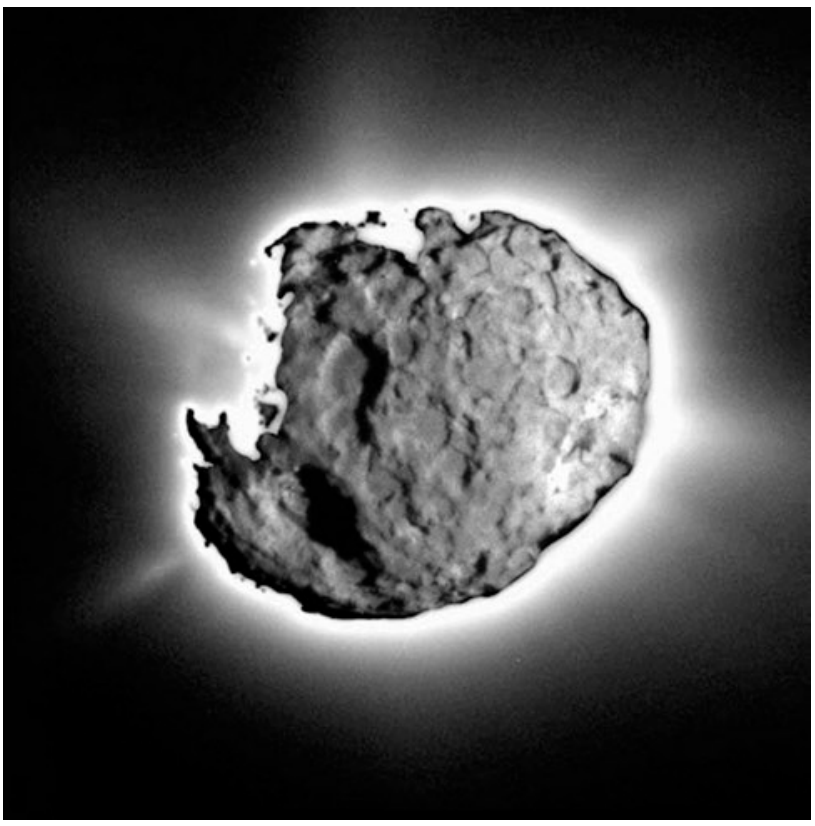

Fig. 1. The surface of the nucleus of comet Wild 2 suggests the presence of a silicate crust that has experienced impact and other processes. Most particularly, the presence of jets suggests opening in the curst through which volatiles and dust are escaped. Thermoluminescence provides a unique way of investigating the radiation and thermal history plus the metamorphic history of particles trapped in the gases constituting the jets. (Brownlee et al., 2006).

gy and composition (such as solar heating or atmospheric entry, excluding the fusion crust). "Metamorphic history" relates to moderate or high temperature and pressure exposures where solid-state recrystallization and changes in mineral structure and composition occur (such as those experienced by isotopic heating and planetary-scale burial).

Thermoluminescence the amount of light produced by a sample since its most recent heating to over $400^{\circ} \mathrm{C}$. The physics of the TL process has been described in detail by McKeever, (1988). In terminology using in TL applications to meteorites, "Natural TL" is the thermoluminescence produced by the sample in the "as received" state, while "induced TL" is the thermoluminescence produced by a sample thermally drained of its natural TL (by heating to $>400^{\circ} \mathrm{C}$ ) and subjected to a standard laboratory radiation dose. The measurement of natural TL provides information on radiation and thermal history of extraterrestrial materials (e.g., Benoit et al., 1994).

The measurement of induced TL informs on the solidstate properties of the samples, such as the degree of crystallization and nature of the crystallized material. These parameters dictate the number and nature of the metastable sites that participate in the luminescence process. Induced TL can inform on phenomena that other techniques cannot. A classical example is the incipient crystallization in the mesostasis of chondrules from primitive chondrites (Sears et al., 1980). This is because it is a highly sensitive technique providing single photon count- ing capabilities and as it is essentially a "bulk" technique. Thus while we think in terms of incipient crystallization of a chondrule mesostasis, it is actually a complete crystallization of highly localized regions, and these are nearly impossible to locate by electron microscopy, and other microbeam techniques, but is readily detected by TL which can detect one part in $\sim 10^{5}$ of the crystalline mesostasis. The extraordinary sensitivity of induced TL to detect "incipient crystallization" provides a unique means to quantify primitive meteorites. The classification of chondrites (i.e. the petrographic types 3.0-3.9) by TL is still in common use after 27 years with TL showing a dynamic rage of $10^{3}$ over type 3 and $10^{5}$ over chondrites as a whole (Sears et al., 1980).

We review here the basic characteristic of thermoluminescence of extraterrestrial materials with a view to applying the technique to small particles, most particularly the Stardust particles. We consider natural TL measurements, induced TL measurements, and the complexities introduced by the collection methods and possible interferences by aerogel.

\section{NATURAL TL AND THE HISTORY OF COME- TARY PARTICLES}

\section{Theoretical background of natural thermolumines- cence}

The level of natural TL observed in a sample is the result of a competition between build up due to radiation exposure and decay due to thermal drainage (Sears and Hasan, 1986). The ratio of the natural TL level observed to the saturated TL value (the maximum value possible) is described by:

$$
\frac{\phi}{\phi_{s}}=\frac{1}{1+\frac{s}{\alpha R \exp \left(-\frac{E}{k T}\right)}}
$$

where $\phi(\mathrm{Gy})$ is the natural TL, $\phi_{s}(\mathrm{~Gy})$ is the value of TL at saturation, dimensionless parameter $s$ is the Arrhenius factor, $\alpha$ is the reciprocal of the mean dose (the dose to fill $1 / \mathrm{e}$ of the traps, $\left.\mathrm{Gy}^{-1}\right), R$ is the dose rate $(\mathrm{Gy} / \mathrm{s}), E$ is the trap depth $(\mathrm{eV}), k$ is Boltzmann's constant $(\mathrm{eV} / \mathrm{K})$ and $T(\mathrm{~K})$ is temperature. Most of the parameters appearing in Eq. 2.1 are characteristics of the material, which can be measured in the laboratory. The exceptions are the two environmental factors, the radiation dose rate and storage temperature.

\section{Physical conditions on the comet surface and subsur- face}

Probably the best insights into processes occurring at and below the surface of comet nuclei are provided by the simulation experiments (Sears et al., 1999). Some results 
are summarized in Fig. 2. It is generally assumed that inside the comet, the ice is largely amorphous, the result of condensation at very low temperature, but within a meter or so of the surface there is radiation-induced crystallization (Colangeli et al., 1992). At some depth there is an evaporation front below which condensation of gases moving inwards occurs and above which diffusion of gases towards the surface occurs. Similarly at the crystallization front, evaporation drives gases move upwards until pressure is sufficient to move some part of the gases downwards, carrying heat into the interior. Throughout the ice there may be considerable amounts of dust and as the surface is constantly eroded by the evaporation of volatiles a dusty crust forms (Whipple, 1951). Thus the albedo of cometary surface is low (Keller et al., 1988). The Deep Impact collision with Comet Tempe 1 released considerable dust (Schultz et al., 2007). It seems likely that most cometary nuclei are rubble piles (Söffler and Düren, 1992), which complicates the process of evaporation and heat transport, and evaporation at the surface is not uniform but occurs mostly by vents where the crust has ruptured (Fig. 1).

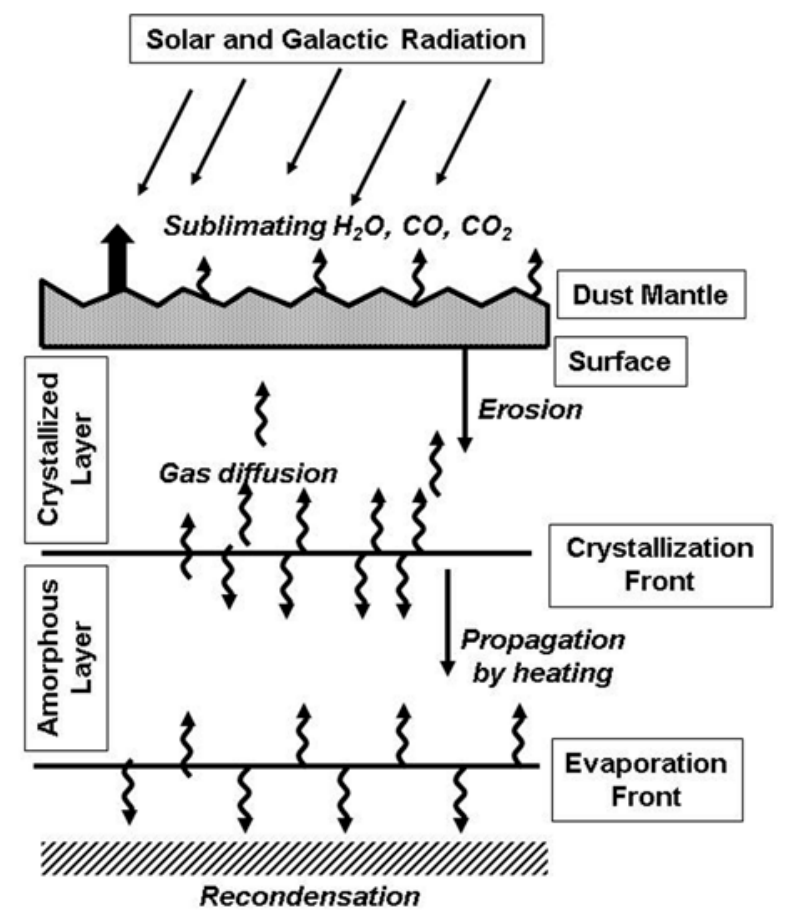

Fig. 2. The physical history of the surface and near-surface of a cometary nucleus as described by Rickman (1991) and observed in laboratory experiments (Sears et al., 1999). Sublimation occurs at temperature fronts $125 \mathrm{~K}$ for $\mathrm{CO}_{2}$-ice and $210 \mathrm{~K}$ for $\mathrm{H}_{2} \mathrm{O}$-ice. Gases move both upwards leading to entrapment of dust grains and ultimate gas loss and build-up of a mantle at the surface and downwards leading to the movement of heat inwards. The dust mantle on the surface contains refractory grains, some of which are entrapped and carried away by gas drag.

\section{Thermal history of cometary dust}

Numerous theoretical and experimental studies exist that predict thermal profiles in a comet nucleus. Typical examples are shown in Fig. 3. Temperatures increase from the cold backplate to the illuminated surface with discontinuities representing the $\mathrm{CO}_{2}$ and $\mathrm{H}_{2} \mathrm{O}$ sublimation fronts at 210 and $125^{\circ} \mathrm{K}$, respectively. Stardust cometary particles have thus probably been heated from the $\sim 150^{\circ} \mathrm{K}$ nucleus temperature to temperatures experienced during transit, landing, and analysis, perhaps as high as $30^{\circ} \mathrm{C}$. In fact, "soak back" (conduction of heat from the heat shield to the interior during the wait for sample extraction) and heating during capture in the aerogel may have caused temperatures higher than $30^{\circ} \mathrm{C}$. We can expect these effects to be common to all Stardust particles and be superimposed on any additional processes experienced by particular grains. The mean life for equilibrating the TL accumulated at, say $150^{\circ} \mathrm{K}$, with laboratory temperatures is $10^{3}-10^{4}$ years (depending on trap depth and the glow curve temperature) (e.g. Benoit and Sears, 1994). Thus, the alteration of the samples due to heating from $\sim 150 \mathrm{~K}$ to $30^{\circ} \mathrm{C}$ should be minimal.

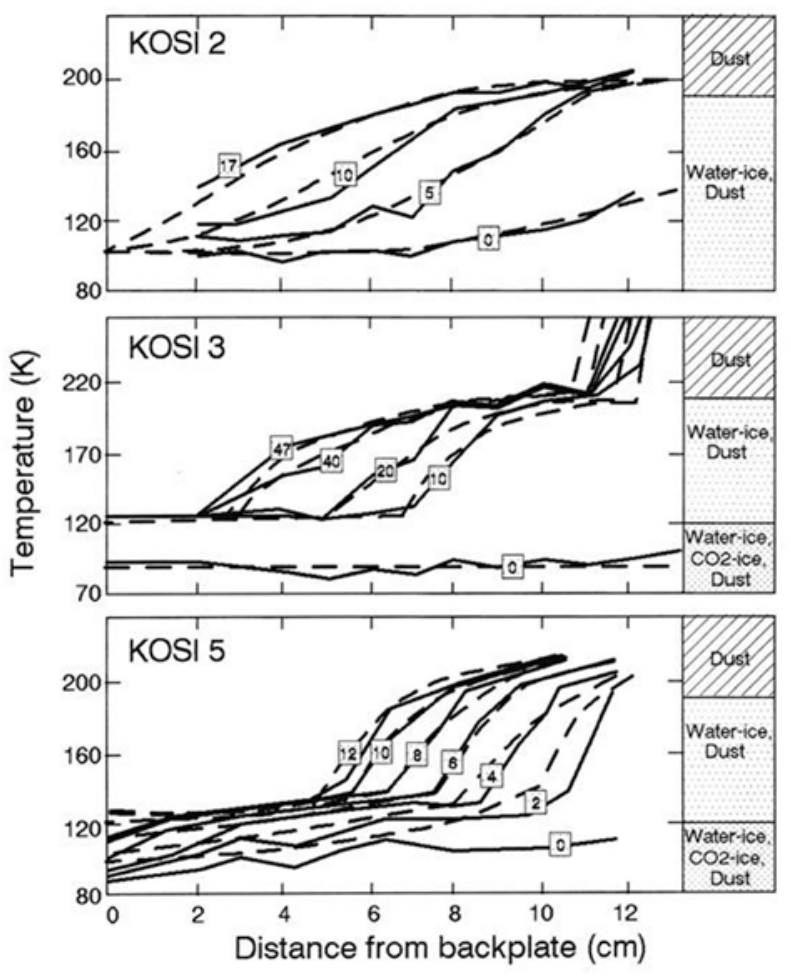

Fig. 3. Summary of the thermal gradients occurring at and below the surface of comets as suggested by Rickman (1991) and consistent with laboratory experiments (Sears et al., 1999). Temperatures increase from the cold backplate of the ices to the illuminated surface, with discontinuities reflecting sublimation of the $\mathrm{CO}_{2}$-ice and $\mathrm{H}_{2} \mathrm{O}$-ice at 125 and $210 \mathrm{~K}$, respectively. The numbers in boxes refer to time in hours. 
IDPs can experience considerable thermal alteration in passing through the atmosphere. Chondritic smooth IDPs were at one time thought to be "unmelted," but Joswiak and Brownlee (1998) and others note that many of them have "weak to prominent magnetite rims, decomposed Fe-sulfides, and/or poorly crystalline phyllosilicates" which imply heating of the surface up to 800 $950^{\circ} \mathrm{C}$, although this did not affect interiors.

\section{Radiation History in cometary dust}

Radiation plays an important role in the history of comets. It is the sublimation of volatiles by solar radiation that produces the crust on the comet nucleus, and determines much of the subsurface structure (Fig. 2) and we can infer radiation profiles from recent work on the nature of the surface of Europa (Fig. 4). Some authors have proposed that below the crust is an "irradiation driven mantle" in which solar and galactic radiation cause loss of volatiles and crystallization of ices (Colangeli et al., 1992).

There is also evidence in the chondritic porous interplanetary dust particles (IDP) of modification by ionizing radiation. The amorphous silicates (including GEMS, particles that are glassy with embedded metal and sulfides) in the IDPs are thought to be the product of radiation-processed presolar crystalline silicate grains (Bradley et al., 1999; Brownlee et al., 1999; Christoffersen and Keller 2006; Joswiak and Brownlee, 2006). Solar flare tracks in these particles indicate lifetimes of $10^{4}-10^{5}$ years, but radiation damage, evidenced as amorphous rims, places a limit on these ages. Natural TL measure-

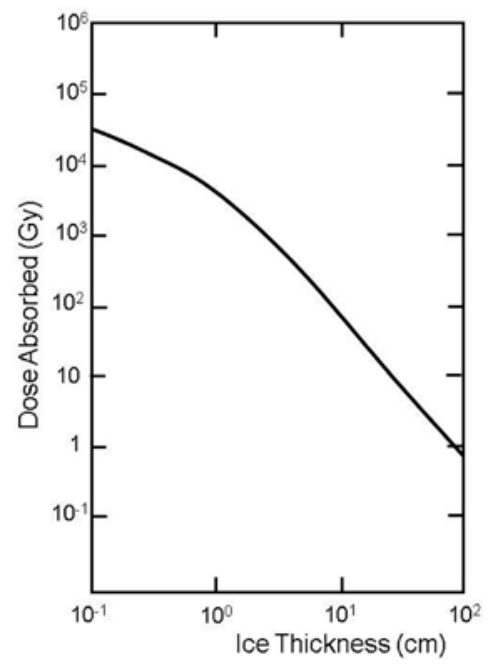

Fig. 4. Radiation dose models for Europa by the Space Studies Board (2000) suggest by measuring the level of natural thermoluminescence caused by radiation absorption we will be able to track the movement of grains through the outer layers of the cometary subsurface. These results suggest that a meter of shielding by ice can cause about two orders of magnitude difference in absorbed dose and therefore natural TL. ments can better elucidate the duration of radiation exposure, since it detects the ionization below the amorphous rim.

\section{Natural thermoluminescence as a tracer of comet particle history}

It is reasonable surmise that particles resting on or near thesurface (say within a meter) experience high radiation levels and high temperatures and the buried samples experience lower temperatures and lower irradiation levels. Thus, by sorting particles into one of four of these categories (Fig. 5), in principle it is be possible to gain insight into the movement of particles through the upper meter or so of the nucleus and determine the extent of recycling of particles in the upper layers of the comet nucleus.

\section{COMPARING THE NATURAL TL LEVEL OF INDIVIDUAL PARTICLES}

To compare the natural TL levels of grains of differing mineralogy and composition and determine their radiation and thermal history, it is necessary to express the natural TL in a manner that normalizes other differences. Determination of the equivalent dose at a specific glow curve temperature enables such normalization. Additional information can be obtained by plotting the equivalent dose as a function of glow curve temperature, normally termed as the plateau test.

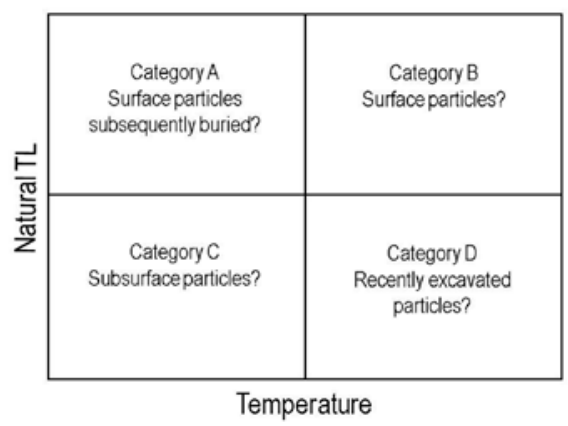

Fig. 5. The scenarios suggested by theoretical studies, laboratory measurements, and observations of cometary nuclei enable four predictions as the thermal and radiation history of cometary dust particles. (1) Particles that experienced high doses by being on the surface and are then protected from electron drainage by burial (Category A). (2) Particles that experienced high doses by being on the surface and that were never buried will have experience both high doses and high temperatures (Category B). (3) Particles that spent virtually all their time buries and were excavated immediately prior to capture will low doses and low temperatures (Category C). (4) Particles that were buried and therefore shielded from radiation that were bought to the surface and collected before radiation exposure was important (Category D). 


\section{Equivalent Dose}

The equivalent dose is the amount of laboratory beta or gamma dose that needs to be applied to the sample to reproduce the natural signal. This is normally computed by calculating the ration of natural and artificial TL multiplied by the laboratory dose for artificial TL (Hasan et al., 1987; Benoit and Sears, 1994; Ninagawa et al., 2000).

\section{Plateau measurement}

Dividing the natural TL signal by the induced TL signal and multiplying by the applied dose results in an equivalent dose as a function of the glow curve temperature (Fig. 6). A plateau at high glow curve temperatures identifies thermally stable regions useful for pottery dating, (Aitken, 1974) and dosimetry (McKeever, 1988). Samples that have been heated or stored at higher temperatures can be identified by the absence of their low temperature signal. An example is the study of Sears (1975) and Singhvi et al. (1982) who measured temperature gradients on various faces of the Barwell and Bansur meteorite during atmospheric entry.

\section{INDUCED TL}

Measurements of the induced TL provide insight into the composition and mineralogy of the particles that, in turn, can provide insights into metamorphic history and thereby provide data on conditions in the early solar system (Sears and Hasan, 1987; Fig. 7). Momentary heating to $500^{\circ} \mathrm{C}$ necessary to drain the natural $\mathrm{TL}$ in order for induced TL to be measured is not sufficient to cause

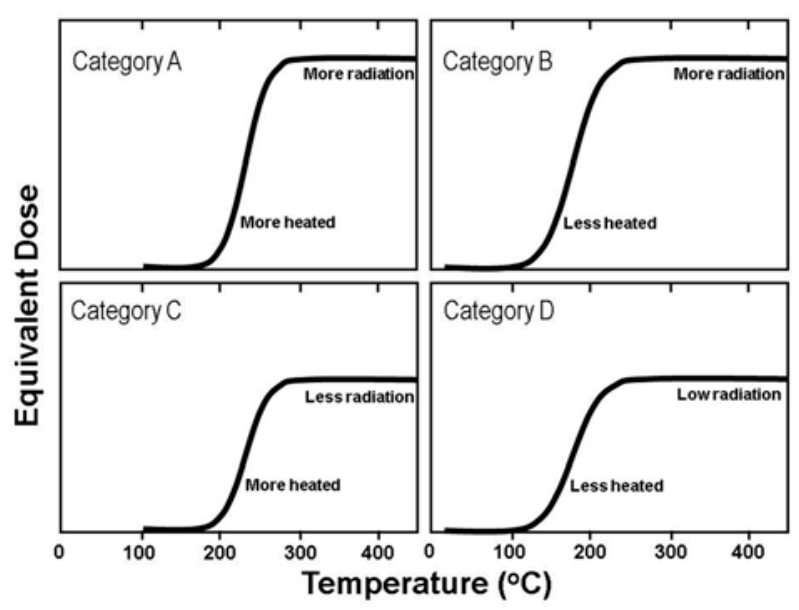

Fig. 6. Natural thermoluminescence stability is best examined by plotting the ratio of natural $T L$ to induced $T L$ as a function of laboratory heating temperature. This is referred to as plotting the "plateau". Above is a schematic illustration of how the plateau will differ for the four categories of particles (each with a unique history) discussed in Fig. 5. Radiation exposure determines the height of the plateau, while temperatures experienced determine the onset of the plateau. mineralogical or compositional changes, but it does slightly darken the samples, which causes a small loss of net TL signal on account of changes in reflectivity and opacity of the grains. This is not normally a problem in these kinds of measurement, but ways to avoid this step are available. A practical significance of induced TL is its high sensitivity and its providing a volume signal. It thus offers prospects of measurements of phenomena are nearly impossible to locate by electron microscopy and other microbeam techniques. For example, can detect changes in one part in $\sim 10^{5}$ of the crystalline material in an amorphous mesostasis can be detected. Changes in induced TL can also be used to quantify shock alteration of meteorites by the loss of signal as crystals melt (Haq et al., 1988).

A guide to the potential for induced TL studies of small particles is provided by the study of the refractory inclusions of the CV chondrite Allende (Sears et al., 1995). Fig. 8 shows the variety of induced TL glow curves produced by eight samples from refractory inclusions studied by Meeker et al. (1983), Meeker (1995); Papanastassiou et al. (1984) and Armstrong and Wasserburg (1981). These curves are the result of a metamorphic series in which low-feldspar was converted to highfeldspar and then melilite. Thus, as long as it is possible to detect sufficient light to produce a glow curve, significant deductions about the mineralogy and metamorphic history of these samples can be made.

Ground-based and spacecraft observations have suggested that crystalline forsterite and enstatite are present in the dust ejected from the nuclei of comets Halley, Hyakutake and Hale-Bopp (Campins, 1999; Jessberger et al., 1988). Spitzer and ground-based observations of Tempel 2 during Deep Impact's impact indicated amor-

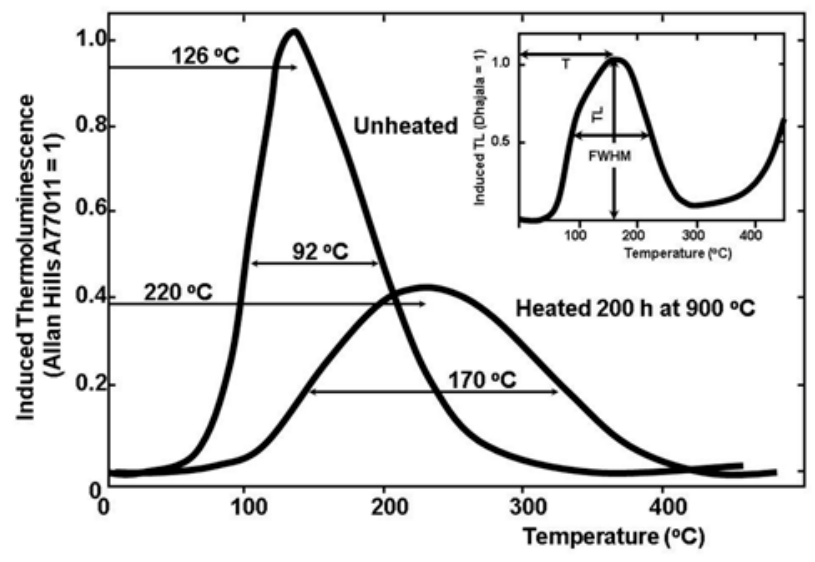

Fig. 7. Glow curves (TL produced against laboratory heating temperature) for an ordinary chondrite in which the $T L$ is produced by feldspar. Laboratory heating experiments combined with X-ray diffraction studies have demonstrated that the TL glow curve is determined by the structure of the mineral, the order form being produced at low metamorphic temperatures and the disordered form produced at high metamorphic temperatures (Guimon et al., 1985). Because of the high sensitivity of $T L$, such information is available for small amounts of feldspar even when buried in an amorphous matrix. 
phous olivine, pyroxene, phyllosilicates and amorphous carbon, and crystalline forsterite, as well as water ice, carbonates, and possibly metal sulfides (Jessberger et al., 1988; Campins, 1999; Meech et al., 2005; Lisse et al., 2006). This combination of materials can be studies by TL. A. Stardust particle with forsterite is shown in Fig. 9.

"Chondritic Smooth" IDPs are generally thought to be of asteroidal origin (Schramm et al., 1989; Brownlee, 1987; Bradley et al., 1994; 1996), but "Chondritic Porous" IDPs, which are chondritic in composition, with anhydrous mineralogy; aggregates of micron and submicron- some porous and some compact, are thought to be of cometary origin, (Schramm et al., 1989; Brownlee, 1987; Bradley et al., 1996; 1998), and perhaps are more representative of the Stardust particle populations. However, if we find evidence for a metamorphic sequence in Stardust cometary particles the assumption that smooth chondritic IDPs are asteroidal becomes suspect.

While IDPs are generally chondritic in composition, individual particles will vary; some being high in carbon and thought to represent material similar to outer solar system asteroids (Thomas et al., 1993). These "asteroids" may, in fact, be related to short period comets and so these carbon-rich particles may actually be cometary in origin. Early data for the Stardust particles suggest that refractory minerals are abundant (Fig. 9). This raises questions about the origin of comets, their relation to asteroids, and the early mixing of material in the solar system. By determining the metamorphic history using TL of these particles, we may be able to answer some of these questions.

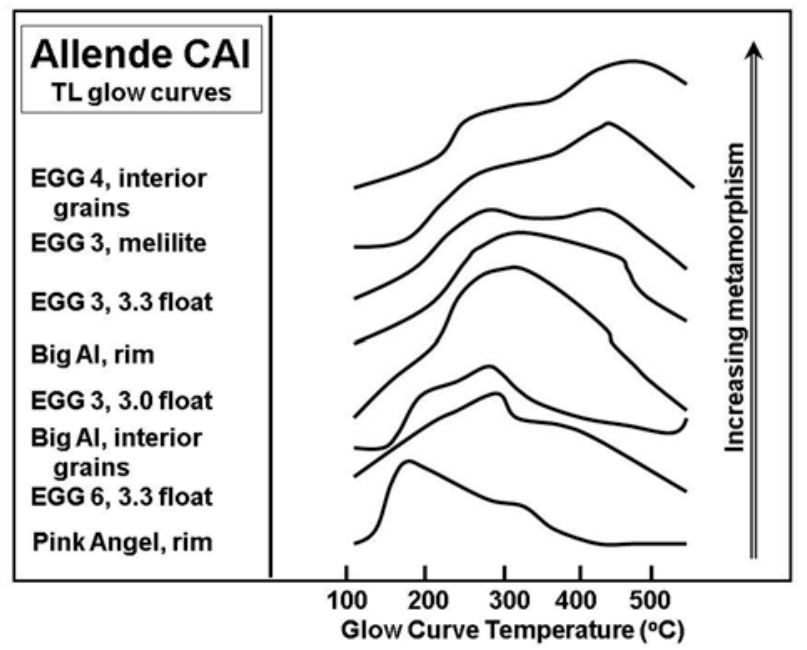

Fig. 8. The variety of induced $T L$ glow curve shapes observed for Allende calcium-aluminum rich inclusions reflected differences in mineralogy that, in turn, reflect differences in metamorphic history (Sears et al., 1995). The least metamorphosed inclusions contain feldspar in the low temperature form (TL peak temperature $\sim 150^{\circ} \mathrm{C}$ ), intermediate levels of metamorphism produce feldspar in the high temperature form (TL peak temperature $\sim 250^{\circ} \mathrm{C}$ ), while the highest levels of metamorphism result in the dominant luminesent mineral being gehlenite (peak $\sim 400^{\circ} \mathrm{C}$ ).

\section{QUANTIFYING THE INDUCED TL OF INDI- VIDUAL PARTICLES}

There are three parameters that can be measured from the TL induced in extraterrestrial samples; the intensity of the induced TL peak, its width, and its temperature (Fig. 8).

\section{Peak intensity (TL sensitivity)}

The intensity of the TL signal induced by a standard test dose, in a sample previously drained of its natural TL signal, is referred to as the TL sensitivity. The TL sensitivity of a given sample depends on the solid-state properties of the mineral or phase responsible (defects, impurity centers and their luminescence emission). Usually just one or two phases in a sample contribute to the total TL and each phase can have specific glow peaks. The intensity of the peaks depends on the amount of the responsible phase and their sensitivity. An example is the $10^{5}$-fold increase in induced TL of ordinary chondrites as feldspar is produced from chondrule glass (Sears et al., 1980).

\section{Peak temperature and width}

The peak temperature and width are parameters that can be successfully related to each other by wellestablished TL theory (Garlick, 1949; McKeever, 1988). Peak temperature is determined by the depth of metastable electron traps below the conduction band called trap depth. Peak width depends on the shape of the Boltzmann distributions and the number of levels. An important example of the relationship between peak temperature

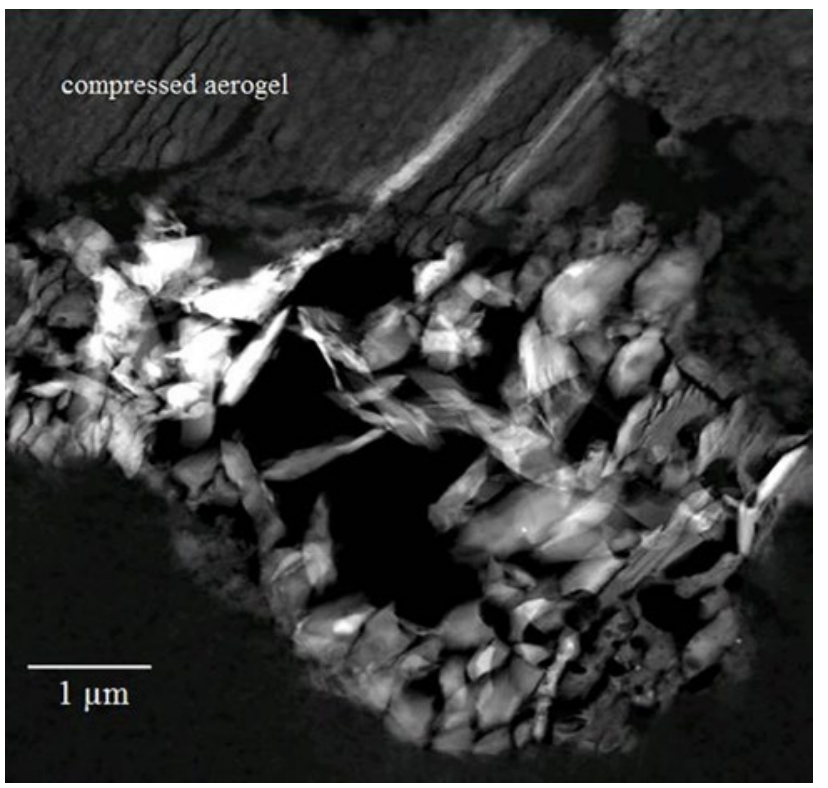

Fig. 9. Refractory grain collected from Comet Wild 2 by the Stardust spacecraft. Refractory minerals tend to be strongly thermoluminescent (Fig. 8), but in the case of the refractory mineral forsterite the luminescence fades rapidly in the presence of a few mol \% Fe. (Geake et al., 1973). 
and width, and their relationship to metamorphic history is displayed by the ordinary chondrites where the phosphor is feldspar (Fig. 8). Experiments with terrestrial feldspars have shown that this reflects conversion of ordered to disordered structure (Hartmetz et al., 1986), and thus is indicative of formation temperature and cooling rate.

\section{COLLECTION ISSUES}

However, all this forgoing would not be possible if the Stardust particles get severely altered by capture in the aerogel. Every study so far has had to consider the effect of heating (and mechanical damage) associated with capture of the particles and the complications arising from mixing with the melted aerogel. It is essential for our measurements to locate the material that is least altered and examine its history. Such a study is possible by sampling aerogel and debris along the track (Fig. 10). The terminal particle is, at least according to the Stardust PI, ".... not much heated at all" (oral presentation of Brownlee et al., 2007 and personal communications). Sure enough, several papers at the recent LPSC seem consistent with this. Some authors appear to have located indigenous organic compounds (Cody et al., 2007), others have measured indigenous inert gas compositions (Palma et al., 2007), and others have located volatile elements indicative of CI compositions (Stephan et al., 2007), a characterization that can only be made on the basis of volatile elements. Yet others have reported volatile-rich minerals indicative of extraterrestrial materials (Joswiak et al., 2007).

This would be loosely analogous to early work on meteorite TL in which the heat penetration in meteorites was measured as they passed through the atmosphere (Sears,

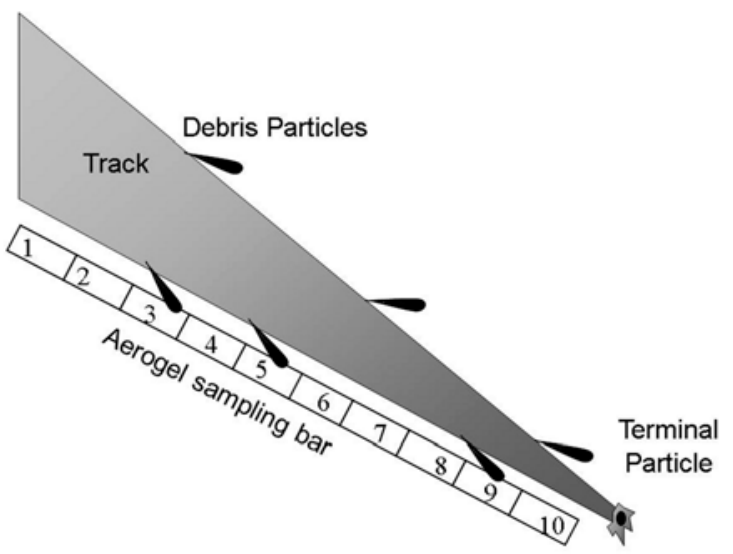

Fig. 10. Summary of a particle capture process in aerogel. The terminal particle is expected to have largely survived capture unaltered, debris particles for can also be examined for comparison purposes. It might also be possible to remove a bar of aerogel to check for crystallization and attempt to quantify conditions along the trail.
1975). The aerogel problem has presented great challenges to many research groups, the comet particles becoming intimately mixed with melted aerogel. We have measured unflown aerogel from the batch that was put on the spacecraft and, as expected, have been unable to detect any TL signal. Neither could we detect TL from an aerogel sample in which a red-hot wire had been pushed. We placed a large piece of aerogel on the heating strip in air and held the sample at $500^{\circ} \mathrm{C}$ for several minutes and thought we detected a slowly growing TL signal, however running blanks showed that this signal was due to oxidation of the heating strip (Fig. 11). While we will maintain constant diligence and run appropriate controls, the aerogel is unlikely to contaminate the TL signal from stardust particles. In fact, if we can detect a signal from aerogel in the vicinity of the particle track we might be able to quantify the conditions along the track.

\section{PRELIMINARY WORK}

\section{Semarkona matrix fragments}

Sedaghatpour and Sears (2009) measured the induced thermoluminescence properties of six $10 \mu \mathrm{m}$ to $400 \mu \mathrm{m}$
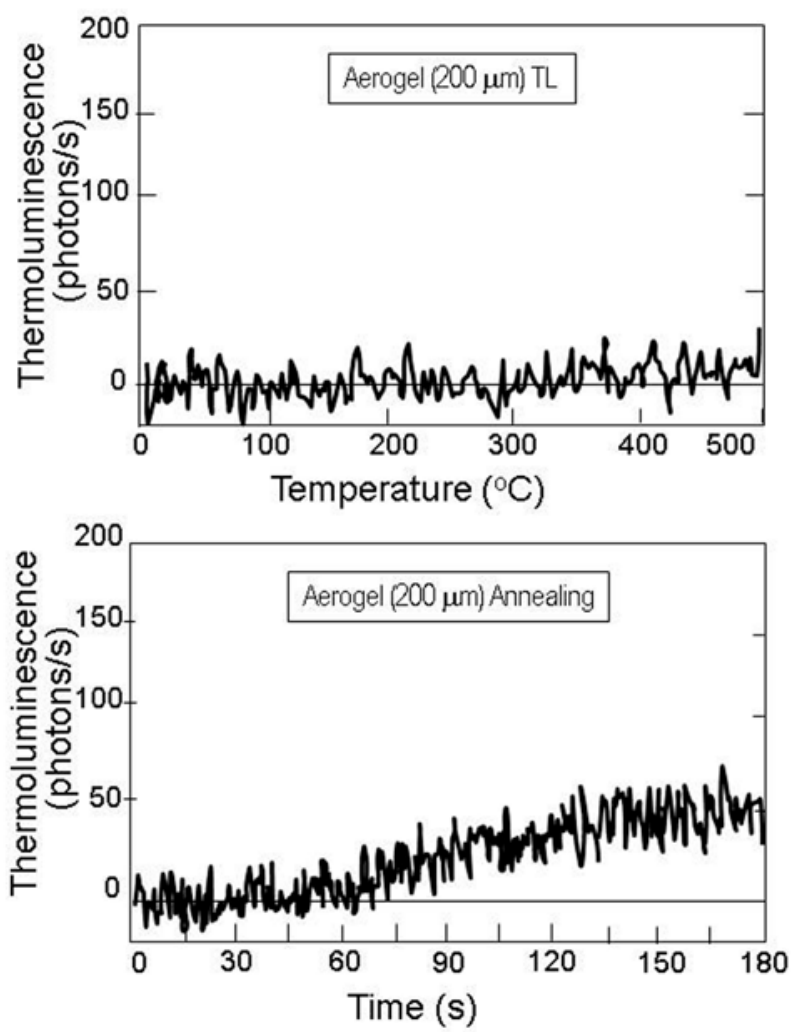

Fig. 11. Thermoluminescence data for aerogel. Above, a glow curve obtained under conditions that would be used for measurements of samples showing no detectable TL signal. Below, a sample of aerogel heated at $500^{\circ} \mathrm{C}$ in air for nearly five minutes showed a small increase. Thus recrystallized aeogel might show a weak signal that can be used to assess thermal history along the track. 
sized matrix samples (Fig. 12). The samples had TL sensitivities comparable with $4 \mathrm{mg}$ of bulk samples of type 3.2-3.4 ordinary chondrites, which is high relative to bulk Semarkona. The other induced TL properties of these samples, TL peak temperatures and TL peak widths, distinguished them from other ordinary chondrite samples where the TL is caused by feldspar. Cathodoluminescence images and other data suggest that the cause of the luminescence in the Semarkona fine-grained matrix is forsterite. Thus forsterite appears to be a major component in many primitive materials, such as nebulae, cometary dust, and Stardust particles.

\section{Antarctic Micrometeorites}

Craig and Sears (2009) measured the thermoluminescence (TL) properties of four micrometeorites, three cosmic spherules and one irregular scoracious particle that they found in a survey of 17 micrometeorites (Fig. 13). These micrometeorites have TL sensitivities ranging from $0.017 \pm 0.002$ to $0.087 \pm 0.009$ (on a scale normalized to $4 \mathrm{mg}$ of the H3.9 chondrite Dhajala). The four micrometeorites have similar TL peak temperatures and TL peak widths and these distinguish them from CI, most $\mathrm{CM}, \mathrm{CV}, \mathrm{CO}$ and ordinary chondrites. However, the TL properties of these micrometeorites closely resemble those of the unusual CM chondrite MAC 87300 and terrestrial forsterites (Fig. 14). Heating experiments on submillimeter chips of a CM chondrite and a H5 chondrite suggest that these TL properties are have not been significantly affected by atmospheric passage. Thus it was suggested that there is no simple linkage between these micrometeorites and the established meteorite clas-

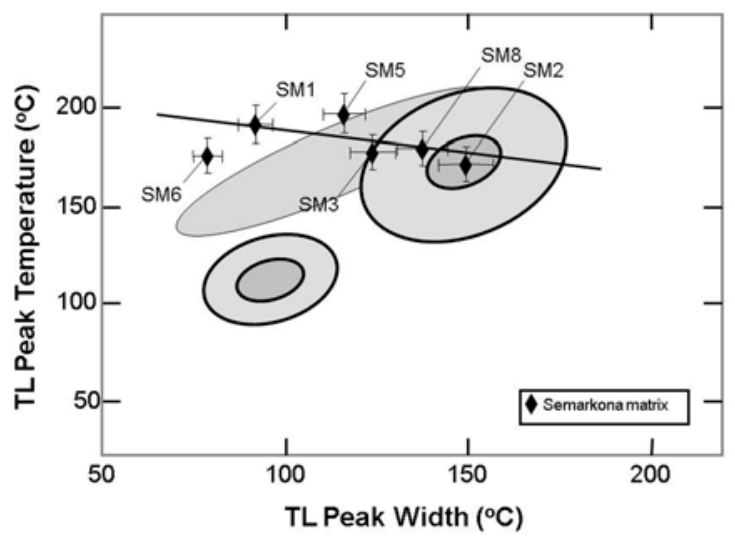

Fig. 12. $T L$ peak temperature vs. $T L$ peak width data for six fragments of the matrix from the Semarkona meteorite compared with the fields shown by terrestrial forsterites and type 3 ordinary chondrites in which the TL phosphor is feldspar. These data indicate that the matrix is usually dominated by forsterite, which is difficult to identify petrographically because it is buried in amorphous material but which is consistent with cathodoluminescence observations. (Craig and Sears, 2009). ses, and that forsterite is an important component of these micrometeorites, as it is in many primitive solar system materials.

\section{Lunar Grains}

Hoyt et al. (1972) measured the thermoluminescence properties of fifty-four 37-74 um grains from the highly
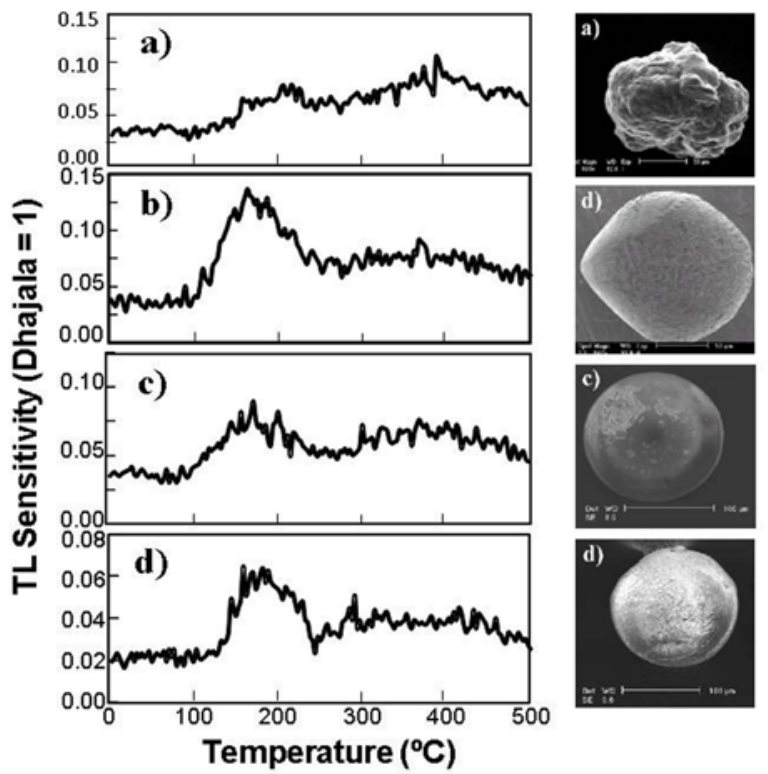

Fig. 13. Thermoluminescence glow curves for four 50-100 $\mu \mathrm{m}$ micrometeorites with SEM images. The micrometeorites produced an easily measurable TL signal. (Sedaghatpour and Sears, 2009).

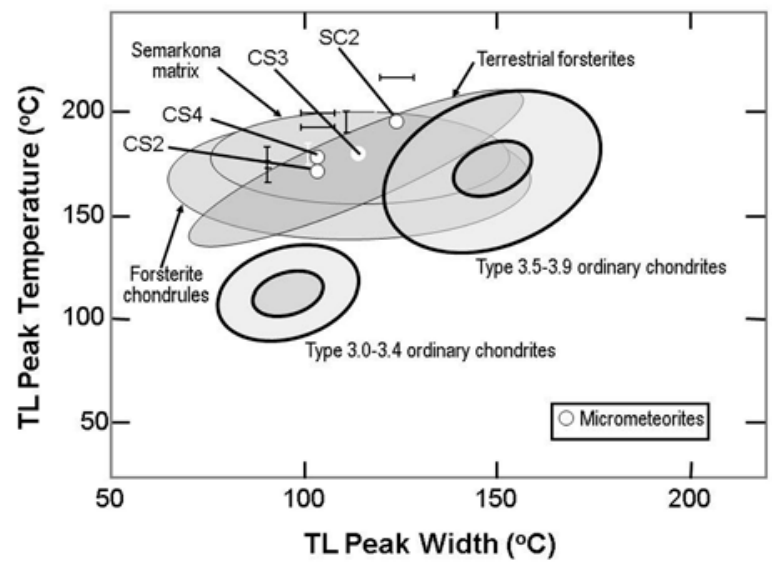

Fig. 14. TL peak temperature vs. TL peak width data for four micrometeorites compared with the fields shown by terrestrial forsterites and type 3 ordinary chondrites in which the TL phosphor is feldspar. The micrometeorites plot to the upper left with respect to the ordinary chondrites and in the field occupied by the terrestrial forsterites suggesting that the forsterite is present in the micrometeorites. (Sedaghatpour and Sears, 2009). 
immature soil sample 12033 and were able to get signals from 14 grains. Most had induced peaks in the $200-250^{\circ} \mathrm{C}$ range of the glow curve and were thought to be due to plagioclase. Others had broad, hummocky, hightemperature peaks they attributed to a $\mathrm{AlSiCa}$ phase (probably anorthite) or occasionally a phosphate. Despite the obvious complexity of individual grains, they were able to detect a profile in the natural TL with depth in the $40 \mathrm{~cm}$ core that they attributed to solar heating near the surface and attenuation of the cosmic radiation at depth.

\section{CONCLUSIONS}

It is now possible to detect thermoluminescence from micrometeorites and 10-400 um fragments of Semarkona type 3.0 ordinary chondrite. Semarkona is the least metamorphosed ordinary chondrite known and has a TL signal $10^{-5}$ times that of common equilibrated ordinary chondrites. The lower size range of particles for which we have detected a signal overlap with the size range for Stardust particles and IDPs. Thus the type of information provided by natural and induced TL techniques that have been developed for extraterrestrial materials over the last 30-40 years can now be applied to the smallest of all extraterrestrial materials. Natural TL studies have the potential to provide information on radiation and thermal history, and might therefore enable insights into the history of cometary particles as they move from the interior to the surface of the nucleus and into interplanetary space. Induced TL has the potential to provide information on the mineralogy and structure of silicate phases in the IDPs and Stardust particles, even when present as trace amounts in a large amorphous and essentially uncharacterized matrix.

\section{REFERENCES}

Aitken MJ, 1974. Physics and archaeology. Interscience Publishers: $181 \mathrm{pp}$.

Armstrong JT and Wasserburg GJ, 1981. The Allende Pink Angel: its Mineralogy, Petrology and the Constraints of its Genesis. Lunar and Planetary Science XII, 25-27.

Benoit PH and Sears DWG, 1994. A recent meteorite fall in Antarctic with an unusual orbital history. Earth and Planetary Science Letters 120(3-4): 463-471, DOI 10.1016/0012-821X(93)90257-A.

Benoit PH, Roth J, Sears H and Sears DWG, 1994. The natural thermoluminescence of meteorites 7: Ordinary chondrites from the Elephant Moraine region, Antarctica. Journal of Geophysical Research - Planets 99(E1): 2073-2085, DOI 10.1029/93JE02474.

Bradley JP, Brownlee DE and Keller LP, 1994. Reflectance Spectroscopy of Individual Interplanetary Dust Particles, Lunar and Planetary Science Conference XXV, Abstract \# 159.

Bradley JP, Keller LP, Brownlee DE and Thomas KL, 1996. Reflectance spectroscopy of interplanetary dust particles. Meteoritics \& Planetary Science 31: 394-402.

Bradley JP, Snow T, Brownlee DE, Keller LP, Flynn GJ and Miller M, 1998. Optical, Mineralogical, and Trace Element Properties of GEMS: Evaluating the Interstellar Connection, Lunar and Planetary Science XXIX, Abstract \# 1737.

Bradley JP, Keller LP, Gezo J, Snow T, Flynn GJ, Brownlee DE and Bowey J, 1999. The 10 and 18 Micrometer Silicate Features of
GEMS: Comparison with Astronomical Silicates, Lunar and Planetary Science XXX, Abstract \# 1835.

Brownlee DE, Joswiak DJ and Bradley JP, 1999. High Spatial Resolution Analyses of GEMS and Other Ultrafine Grained IDP Components. Lunar and Planetary Science XXX, Abstract \# 2031.

Brownlee D and 182 others, 2006. Comet 81P/Wild 2 Under a Microscope. Science 314(5806): 1711-1716, DOI 10.1126/science.1135840.

Brownlee DE, Joswiak D, Bradley J and Matrajt G, 2007. The Origin of Crystalline Silicates in Comets and Large Scale Mixing in the Solar Nebula. Lunar and Planetary Science XXXVIII, Abstract \# 2189.

Campins H, 1999. Interstellar Signatures in Cometary Solids. Lunar and Planetary Science XXX, Abstract \# 1542.

Chi M, Ishii H, Toppani A, Browning ND and Bradley JP, 2007. Does Comet Wild-2 Contain GEMS? Lunar and Planetary Science XXXVIII, Abstract \# 2010.

Christoffersen R and Keller L, 2006. Space Plasma Ion Processing of IDP Sulfides: A Comparison to Silicates Based on In-Situ TEM Ion Irradiation Experiments. Lunar and Planetary Science XXXVII, Abstract \#1738.

Cody GD, Yabuta H, Alexander CMO'D, Araki T and Kilcoyne ALD, 2007. Placing Comet 81P/Wild 2 Organic Particles into Context with Chondritic Organic Solids. Lunar and Planetary Science XXXVIII, Abstract \# 2286.

Colangeli L, Bossoletti E and Schwehm G, 1992. Physical models of comet nuclei, A review. In: Hunt J and Guyenne TD, eds., Physical Mechanics of Comet Materials. European Space Agency, special publication 302: 17-22.

Craig JP and Sears DWG, 2009. The fine-grained matrix of the Semarkona LL3.0 ordinary chondrite: An induced thermoluminescence study. Meteoritics \& Planetary Science 44(5), 643-652, DOI 10.1111/j.1945-5100.2009.tb00760.x.

Brownlee DE, 1987. Morphological, Chemical and Mineralogical Studies of Cosmic Dust [and Discussion]. Philosophical Transactions of the Royal Society of London. Series A, Mathematical and Physical Sciences 323(1572): 305-311, DOI 10.1098/rsta.1987.0087.

Flynn GJ and 79 others, 2006. Elemental Compositions of Comet 81P/Wild 2 Samples Collected by Stardust. Science 314(5806): 1731-1735, DOI 10.1126/science.1136141.

Garlick GFJ, 1949. Luminescent Materials. Clarendon Press: 271pp.

Geake JE, Walker G, Telfer DJ, Mills AA and Garlick GFJ, 1973. Luminescence of lunar, terrestrial, and synthesized plagioclase caused by $\mathrm{Mn}^{2+}$ and $\mathrm{Fe}^{3+}$. Proceedings of the Lunar Science Conference 4, 3181 .

Guimon RK, Keck BD and Sears DWG, 1985. Chemical and physical studies of type 3 chondrites - IV: Annealing studies of a type 3.4 ordinary chondrite and the metamorphic history of meteorites. Geochimica et Cosmochimica Acta 19: 1515-1524.

Haq M, Hasan FA and Sears DWG, 1988. Thermoluminescence and the shock and reheating history of meteorites - IV: The induced TL properties of type 4-6 ordinary chondrites. Geochimica et Cosmochimica Acta 52: 1679-1689.

Hartmetz CP, Ostertag R and Sears DWG, 1986. A thermoluminescence study of experimentally shock-loaded oligoclase and bytownite. Journal of Geophysical Research 91: E263-E274, DOI 10.1029/JB091iB13p0E263.

Hasan FA, Haq M and Sears DWG, 1987. The natural thermoluminescence levels in meteorites I. 23 meteorites of known Al-26 content. Journal of Geophysical Research 92: E703-E709, DOI 10.1029/JB092iB04p0E703.

Hörz F and 43 others, 2006. Impact Features on Stardust: Implications for Comet 81P/Wild 2 Dust. Science 314(5806): 1716-1719, DOI 10.1126/science.1135705.

Hoyt HP Jr., Walker RM, Zimmerman DW, Zimmerman J, 1972. Thermoluminescence of individual grains and bulk samples of lunar fines. Proceedings of the Lunar Science Conference 2: 2997.

Jessberger EK, Christoforidis A and Kissel J, 1988. Aspects of the Major Element Composition of Halley's Dust. Nature 332: 691695, DOI 10.1038/332691a0. 
Joswiak DJ and Brownlee DE, 1998. Atmospheric Entry Melting in 515 Micrometer Hydrous IDPs: Evidence from Analytical TEM Studies and Pulse-Heating Experiments. Lunar and Planetary Science XXIX, Abstract \# 1929.

Joswiak DJ and Brownlee DE, 2006. Non-GEMS Silicate Glasses in Chondritic Porous Interplanetary Dust Particles, Lunar and Planetary Science Conference XXXVII, Abstract \# 2190.

Joswiak DJ, Matrajt G. Brownlee DE, Westphal AJ and Snead CJ, 2007. A Roedderite-bearing Terminal Particle from Stardust Track 56: Comparison with Rare Peralkaline Chondrules in Ordinary Chondrites. Lunar and Planetary Science XXXVIII, Abstract \# 2142.

Keller HU, Kramm R and Thomas N, 1988. Surface features on the nucleus of Comet Halley. Nature 331, 227-231, DOI $10.1038 / 331227 \mathrm{a} 0$.

Keller LP and 32 others, 2006. Infrared Spectroscopy of Comet 81P/Wild 2 Samples Returned by Stardust. Science 314(5806): 1728-1731, DOI 10.1126/science.1135796.

Lisse CM, VanCleve J, Adams AC, A'Hearn MF, Fernández YR, Farnham TL, Armus L, Grillmair CJ, Ingalls J, Belton MJS, Groussin O, McFadden, LA, Meech KJ, Schultz PH, Clark BC, Feaga LM, Sunshine JM, 2006. Spitzer Spectral Observations of the Deep Impact Ejecta. Science 313(5787): 635-640, DOI 10.1126/science.1124694.

McKeegan KD and 46 others, 2006. Isotopic Compositions of Cometary Matter Returned by Stardust. Science 314(5806): 1724-1728, DOI 10.1126/science.1135992.

McKeever SWS, 1988. Thermoluminescence of Solids. Cambridge University Press: $390 \mathrm{pp}$.

Meech KJ, Ageorges N, A'Hearn MF, Arpigny C, Ates A, Aycock J, Bagnulo S, Bailey J, Barber R, Barrera L and 199 coauthors, 2005. Deep Impact: Observations from a Worldwide Earth-Based Campaign. Science 310: 265-269, DOI 10.1126/science.1118978.

Meeker GP, 1995. Formation of CAIs by Partial Melting and Accretion During Heating in a Gas of Solar Composition. Lunar and Planetary Science XXIV: 947-948.

Meeker GP, Wasserburg GJ and Armstrong JT, 1983. Replacement textures in CAI and implications regarding planetary metamorphism. Geochimica et Cosmochimica Acta 47: 707-721.

Ninagawa K, Soyama K, Ota M, Toyoda S, Imae N, Kojima H, Benoit $\mathrm{PH}$ and Sears DWG, 2000. Thermoluminescence studies of ordinary chondrites in the Japanese Antarctic meteorite collection, II: New measurements for thirty type 3 ordinary chondrites. Antarctic Meteorite Research 13: 112-120.

Palma RL, Pepin RO, Schlutter D and Simones J, 2007. Helium and Neon Isotopic Compositions from Stardust Aerogel Particle Tracks Lunar and Planetary Science XXXVIII, Abstract \# 2032.

Papanastassiou DA, Brigham CA and Wasserburg GJ, 1984. Search for MG Isotopic Signatures in Allende. Lunar and Planetary Science $\mathrm{XV}, 629-630$.

Rickman H, 1991. The thermal history and structure of cometary nuclei. In: Comets in the post-Halley era. 2, 733-760.

Rietmeijer FJM, 2007. Challenges to Understand Aerogel Contaminated by Hypervelocity-impacted. Lunar and Planetary Science XXXVIII, Abstract \# 1082.

Sandford SA and 54 others, 2006. Organics Captured from Comet 81P/Wild 2 by the Stardust Spacecraft. Science 314(5806): 17201724, DOI 10.1126/science.1135841.
Schramm LS, Brownlee DE and Wheelock MM, 1989. Major element composition of stratospheric micrometeorites. Meteoritics 24: 99112

Schultz PH, Eberhardy CA, Ernst CM, A'Hearn MF, Sunshine JM and Lisse CM, 2007. The Deep Impact oblique impact cratering experiment. Icarus 190(2), 295-333, DOI 10.1016/j.icarus.2007.06.006.

Sears DW, 1975. Temperature gradients in meteorites produced by heating during atmospheric passage. Modern Geology 5: 155-164.

Sears DWG and Hasan FA, 1986. Thermoluminescence and Antarctic meteorites. In: Annexstad JO, Schultz L, and Wanke H, eds., Proc. 2nd Workshop on Antarctic Meteorites LPI Technical Rept. 86-01. Lunar and Planetary Institute, Houston: 83-100.

Sears DWG and Hasan FA, 1987. Type 3 ordinary chondrites: A review. Surveys in Geophysics 9(1): 43-97, DOI 10.1007/BF01903400.

Sears DW, Grossman JN, Melcher CL, Ross LM and Mills AA, 1980 Measuring the metamorphic history of unequilibrated ordinary chondrites. Nature 287: 791-795, DOI 10.1038/287791a0.

Sears DWG, Symes SP, Guimon RK and Benoit PH, 1995. Chemical and physical studies of type 3 chondrites XII: The metamorphic history of $\mathrm{CV}$ chondrites and their components. Meteoritics 30: 707-714.

Sears DWG, Kochan H and Huebner WF, 1999. Simulation experiments and surface processes on comets. Meteoritics and Planetary Science 34(4): 497-525, DOI 10.1111/j.1945-5100.1999.tb01360.x.

Sedaghatpour F and Sears DWG, 2009. Characterization of Antarctic micrometeorites by thermoluminescence. Meteoritics \& Planetary Science 44(5), 653-664, DOI 10.1111/j.19455100.2009.tb00761.x.

Singhvi AK, Pal S and Bhandari N, 1982. Ablation Characteristics of Meteorites Based on Thermoluminescence and Track Studies. PACT 6: 404-410.

Space Studies Board, 2000. Preventing the Forward Contamination of Europa, 2 Europa. In National Research Council. A Science Strategy for the Exploration of Europa, National Academy Press, Washington, D.C., 1999. Updated 6/29/00.

Stephan T, Flynn GJ, Sandford SA, Zolensky ME, 2007. TOF-SIMS Analysis of Comet Wild 2 Particles Extracted from Stardust Aerogel. 38th Lunar and Planetary Science Conference, (Lunar and Planetary Science XXXVIII), held March 12-16, in League City, Texas. LPI Contribution No. 1338, p.1126

Stoeffler D and Düeren H, 1992. Cometary analogue material - Types, tests, and results. Annales Geophysicae 10, 206-216.

Thomas KL, Blanford GE, Keller LP, Klock W and McKay DS, 1993. Carbon abundance and silicate mineralogy of anhydrous interplanetary dust particles. Geochimica et Cosmochimica Acta 53: 15511556

Whipple FL, 1951. A Comet Model. II. Physical Relations for Comets and Meteors. Astrophysical Journal 113, 464-474.

Zolensky ME, Pieters C, Clark B and Papike JJ, 2000. Invited Review Small is beautiful: The analysis of nanogram-sized astromaterials. Meteoritics and Planetary Science 35(1): 9-29, DOI 10.1111/j.1945-5100.2000.tb01970.x.

Zolensky ME and 74 others, 2006. Mineralogy and petrology of Comet 81P/Wild 2 nucleus samples. Science 314(5806): 1735-1739, DOI $10.1126 /$ science. 1135842 . 